\title{
Proceder ARTístico AGENCIADO POR MUJERES: las tejedoras mayas en Los Altos de Chiapas
}

\author{
Artistic Proceeding Promoted by Women: Female Mayan Weavers from Los Altos de Chiapas
}

\author{
Claudia Adelaida Gil-Corredor
}

Resumen: En este artículo se exponen, desde la noción de agenciamiento, descripciones analíticas de una práctica artística milenaria, el tejido, llevada a cabo por las actuales mujeres mayas tsotsiles y tseltales de Los Altos de Chiapas. Con ello se busca evidenciar el carácter interrelacional de la estética cultural de un pueblo originario que hace del tejido una forma de vida en la que vincula aspectos de su herencia histórica, con su sentir colectivo y sus actividades cotidianas. Asimismo, en el tejido se muestran los agenciamientos de las mujeres, quienes a través de su actividad como tejedoras se convierten en agentes de transformación y resistencia.

Palabras clave: artes textiles, pueblos indígenas, mujeres.

Summary: The present article exposes analytic descriptions made from notions of agency — multiple reciprocity — to a millenarian artistic practice regarded by actual Mayan women Tsotsil and Tseltal from Los Altos de Chiapas. This notion evidences the inter-relational character of cultural aesthetic from an original town, what makes one of its artistic practices a living style, in which relates multiple aspects from its historic heritage, shared feelings and daily activities. Multiple connections which frame an agency of women as an artistic device circulated by intensities turning it into an agent of transformation and resistance.

Keywords: textile arts, indigenous peoples, textile products, women.

Claudia Adelaida Gil Corredor. Doctora en Historia del Arte por Casa Lamm, Ciudad de México. Profesora investigadora de tiempo completo en la Facultad de Artes de la Universidad de Ciencias y Artes de Chiapas, México. Temas de especialización: relación entre arte y política. Correo electrónico: adelaida.gil@gmail.com.
Enviado a dictamen: 5 de septiembre de 2016.

Aprobación: 20 de marzo de 2017.

Revisiones: 2. 


\section{Introducción}

$\mathrm{P}$ ara asumir las actuales prácticas artísticas textiles de los pueblos originarios de Los Altos de Chiapas como un "agenciamiento" — aquel capaz de producir cambios en su entorno-, propuesto por "agentes culturales", es necesario pensar estas prácticas a partir de su lógica interrelacional; es decir, es preciso reconocer su accionar artístico desde una dinámica de correspondencia entre los siguientes aspectos: su carácter ritual, su herencia histórica, su capacidad de trasformación y adaptación, su vínculo con la cotidianidad, su carácter formal y técnico, y, por último, la presencia de la mujer implícita en la dinámica. Estos aspectos, en su conjunto, configuran el proceso de la práctica textil maya actual en Los Altos de Chiapas.

Eslacapacidaddecorrespondenciaointerconectividad de los elementos mencionados la que sitúa a la práctica artística textil maya actual como un "agenciamiento cultural" movilizado por "agentes culturales" cuyas interacciones creativas irrumpen en escenarios sociales o políticos para transformarlos, potencializando diversas dimensiones o estratos artístico-políticos que, a medida que se diversifican, modifican su naturaleza y aumentan sus conexiones en pro de una intervención localizada que apuesta por la transformación sociocultural, al tiempo que defiende un legado artístico histórico y produce otros agenciamientos.

En ese horizonte, el presente artículo, producto de una investigación de corte cualitativo, ofrece algunas descripciones interpretativas de esta práctica artística milenaria, en primer lugar, desde la perspectiva del filósofo francés Gilles Deleuze, para quien el "agenciamiento" hace referencia a una multiplicidad como territorialidad deslindada y, por ello, con capacidad de devenir en otros agenciamientos (Deleuze y Guattari, 2002), y, en segundo lugar, desde la noción de "agente cultural", que hace referencia a aquellas personas, en este caso mujeres, que por medio de su trabajo con la cultura se transforman en líderes sociales y políticos con capacidad para intervenir sobre sus realidades. Estas dos perspectivas ofrecen la posibilidad de comprender la práctica textil de Los Altos de
Chiapas como alternativa de cambio o resistencia ante los procesos de deshumanización que se viven hoy día como resultado de la economía global, además de que nos permiten formular una posible perspectiva de abordaje de un arte que frecuentemente pasa desapercibido por considerarse como una producción folclórica de comunidades ocultas, frente a un mercado de productos industriales altamente desarrollados. Estas perspectivas permitirán, a su vez, presentar la capacidad de "afectación" o transformación propia de algunas acciones artísticas agenciadas por mujeres.

Para la presentación de cada una de las descripciones que conforman este texto se usa la noción de "dimensión", la cual se asume como una magnitud que posibilita la multiplicidad de sentidos. No se pretende exponer algunos aspectos de la práctica artística textil a partir de su división en fragmentos que generen significados cerrados, como si el objetivo consistiera en descifrar este arte ancestral, sino, por el contrario, ofrecer una experiencia de acercamiento a las diferentes facetas y magnitudes del agenciamiento

\section{Primera dimensión: los textiles como herencia histórica de un sentir colectivo}

La práctica artística textilera en Los Altos de Chiapas es una herencia maya que pervive en los productos elaborados por las actuales mujeres tsotsiles y tseltales, como un elemento de identidad que les permite a ellas y a sus comunidades perdurar dentro de un mundo que en ciertos casos les ha sido hostil y proyectarse en el tiempo.

La producción textilera entre los mayas en las diferentes épocas de su larga historia de avanzada cultura artística, material y científica constituye un hito que define en gran medida su identidad y su estética cultural a lo largo de los tiempos. Si bien la grandiosidad alcanzada por este pueblo como civilización que hizo grandes aportes a la humanidad ya no existe, aún quedan de él no sólo las estelas, dinteles, códices, templos, monumentos y cerámicas custodiados y protegidos por museos y organismos oficiales, sino también sus descendientes directos constituidos, en el 
caso del estado de Chiapas, por los tsotsiles y tseltales, entre otras etnias. Ellos practican una de las actividades que, junto con las matemáticas y otras ciencias y artes, identificó a la cultura maya prehispánica: la producción, elaboración y uso de textiles. De esta manera, la historia de los mayas continúa viva en esta región de Los Altos de Chiapas.

Los productos textileros forman parte de la herencia histórico-artística de un pasado maya que subsiste en el telar de cintura, en el bordado y en los trajes de uso cotidiano y ceremonial. Esta herencia - a pesar de los cambios sufridos como consecuencia del transcurso del tiempo y de los acontecimientos sociales, culturales, económicos y políticos - se mantiene y da identidad a las comunidades de los pueblos originarios, ${ }^{1}$ que se ven reflejadas en los objetos que tejen, usan y venden. Un elemento específico que muestra la relación de este pueblo con su medio natural, con su contexto social y político, con la ciencia matemática legada y con el cosmos infinito lo constituye la llamada toca que se utiliza en el municipio de San Pedro Chenalhó. ${ }^{2}$

Las mujeres de este municipio se distinguen por el uso de esta toca, un manto o rebozo que portan diariamente para abrigar su torso. Se trata de una prenda de vestir que se elabora usando como base una tela blanca de aproximadamente 80 por 140 centímetros sobre la que se realizan bordados de color uva oscuro o rojo, los cuales reflejan unos rasgos expresivos y una estructura compositiva que han perdurado durante muchos años. La estructura compositiva que actualmente se usa tuvo su origen hace aproximadamente setenta años, y en este período sólo ha experimentado ligeros cambios.

El grosor de los bordados varía a partir del número de hilos que elige la tejedora: tres, cinco, siete, nueve o hasta trece hilos. En la parte inferior de la tela las tejedoras bordan una línea horizontal en la que apoyan toda la composición, como si se tratase de un lienzo en el que pintan. Sobre este eje horizontal bordan siete columnas, cada una de las cuales hace las veces del tallo de una planta que en su extremo más alto expone una flor. De manera ascendente, esta figura que asemeja a una flor es bordada tres o cuatro veces, figurando ser nubes de un cielo en movimiento.
Por otro lado, en los detalles de la estructura compositiva que decoran esta prenda se observan bordados de pequeños rombos con centros de color elaborados con hilos amarillos, rojos, azules o hasta fluorescentes. Estos variados tonos aparecen como acentos cromáticos que enriquecen plásticamente la prenda dotándola de los gestos expresivos de la tejedora.

Tales acentos caracterizan la acción creadora implícita en el bordado, en el que cada mujer realiza algunas variantes, por ejemplo, en el tamaño de la flor, en el grosor de la planta o en el diseño de las formas, para con ello dotar a cada prenda de ricas y sutiles diferencias. Es en la composición donde el espacio se modula como tierra-planta-flor-nube en expansión.

En la fototeca del Centro Cultural Na-Bolom de San Cristóbal de Las Casas, en Chiapas, se encuentran archivadas imágenes de diversas festividades del pueblo de Chenalhó tomadas desde los años cincuenta hasta los ochenta del siglo XX por la etnógrafa suiza Gertrude Duby Blom. En las tocas registradas por esta investigadora hace ya casi setenta años se observa la misma estructura compositiva que la utilizada en las tocas actuales. La diferencia más sobresaliente consiste en que las de los años cincuenta tienen bordados más sencillos o sutiles, mientras que las actuales muestran mayor complejidad y variedad en el color.

Esta doble vía entre cambio y permanencia reafirma el carácter identitario de la prenda, pues los rasgos que perduran en ella con el paso del tiempo hacen las veces de lazo que integra herencias desde las que se vinculan los sujetos. A su vez, las variaciones dejan ver las acciones de creación artística de las mujeres de este pueblo, que dotan de flexibilidad y apertura a sus caracteres identitarios. Lo anterior implica asumir la noción de identidad como un proceso en permanente construcción a partir de la estrecha interacción simbólica entre sujetos, tal como señala el investigador chileno Jorge Larraín (2003), y no como una esencia o disposición interna que permanece inamovible con el paso del tiempo.

La construcción de identidad heredada y actualizada por las comunidades mayas actuales también se 
evidencia en las semejanzas que se identifican entre las escenas inscritas en las tocas y las de algunas piezas mayas clásicas. Es decir, las similitudes existentes entre las piezas actuales y las de los mayas clásicos dejan ver rasgos comunes a partir de los cuales es posible caracterizar una herencia que se ha adaptado con el paso del tiempo y ha permitido la construcción de posesiones o categorías colectivas que han ido construyendo la identidad de este pueblo originario. Según expone Larraín, existen tres elementos que componen toda identidad: las categorías colectivas, las posesiones y los otros. Cada uno de estos elementos representa materiales simbólicos adquiridos en la interacción social (Larraín, 2003).

La toca como material simbólico construido desde la interconexión entre elementos plásticos, creencias mágico-religiosas y prácticas cotidianas evidencia un carácter identitario de los actuales pueblos mayas de Los Altos de Chiapas. En este atuendo se observa la relación entre un elemento artístico, la práctica de la cosecha y una acción ritual, componentes que se condensan en un manto elaborado por las mujeres y que ellas mismas usan a diario. En su construcción plástica se encuentra un eje tendido de forma horizontal que representa la tierra, sobre la que crecen siete plantas florecidas con destellos de luz convertidos en colores brillantes. De las plantas ascienden tres flores que tocan el cielo para convertirse en nubes, en estrellas. Ciclos terrestre y celeste. Cultivo. Planta que crece de la tierra y florece para tocar el cielo y ofrendar por las buenas cosechas.

Algo similar a lo que se descubre en la toca actual se observa en el tablero del Templo de la Cruz Foliada de los mayas clásicos en Palenque. Este tablero muestra un relieve logrado con líneas firmes que permiten la representación de una ofrenda muy expresiva. En él se encuentra un motivo central en forma de cruz flanqueada por dos individuos, uno pequeño con un complejo vestuario y otro más alto cubierto solamente con máxtlatl. ${ }^{3}$ La escena está enmarcada, de derecha a izquierda, por textos jeroglíficos extensos en los que se encuentra la fecha 692. La descripción de esta pieza que hace la historiadora del arte mexicana Beatriz de la Fuente es la siguiente:
La composición vertical de tres segmentos, los dos laterales correspondientes a los dos sacerdotes ofrendantes, y el central correspondiente al símbolo venerado, se encuentra equilibrada por una estructura horizontal de tres niveles. La inferior, el interior de la tierra, es el mascarón descarnado de la muerte acompañado en un lado por un mascarón terráqueo $y$ en el otro por una deidad terrestre que sale de un caracol y sostiene la planta del maíz, que lleva hojas y cabezas humanas probablemente equivalentes a la deidad joven del maíz [...] Un segundo nivel, central, lleva motivos que representan lo orgánico, lo vital. Las cruces, signo convencional de la planta del maíz, o símbolo cósmico de la vida, que en la mentalidad maya tenía significación análoga [...] Un tercer nivel superior con el pájaro quetzal de máscara serpentiforme señala la dimensión celeste (De la Fuente, 1965: 136).

Estos ejemplos del arte maya, la toca y el tablero, dejan ver la importancia de la acción ritual relacionada con la cosecha del maíz. Son escenas que capturan una acción de culto y agradecimiento por las cosechas. En los dos casos se ve con precisión una relación entre lo terrestre y lo celeste y, aunque con formas diferentes, hay similitudes simbólicas tal como se observa en la figura 1 .

Por otro lado, se identificó otra similitud entre la toca actual y un rasgo expresivo de los mayas clásicos. Se trata de un tipo de ilusión óptica que usaban los pintores de los murales de Bonampak, lograda desde el manejo del color. Según lo expone la historiadora del arte y arqueóloga Sophia Pincemin, en estos murales la ilusión óptica se observa en la falda de uno de los personajes, en la que se percibe que la tela es de color rojo con motivos de volutas en azul, pero en realidad el dibujo está en rojo sobre fondo azul. Al respecto esta investigadora dice: "dichas ilusiones ópticas muestran, por una parte, el conocimiento total de la perspectiva que tenían los artistas mayas. El hecho de poder jugar con la visión para dar la impresión de realidad expresa su dominio sobre los problemas mayores de la pintura" (Pincemin, 2008: 67-68). 
Por otro lado, en la toca actual se usan incrustaciones de pequeños puntos de color fluorescente o vivo para crear ilusiones ópticas de relieve. Es decir, a partir del contraste entre los colores la tejedora logra acentuar volúmenes mediante la vibración entre diversos tonos. Por ejemplo, en el tallo de la planta de la toca suelen tejer un centro de color intenso, o en el eje de tierra acentúan rombos usando el contraste de color, de tal forma que la repetición de éstos crea un ritmo visual que recorre la composición dándole movimiento. Es un movimiento de adelante hacia atrás, a partir del cual se destaca el relieve de las formas mediante el juego entre fondo y forma. El uso de estos colores permite mostrar la destreza y riqueza de conocimientos en torno al diseño, el color y el volumen por parte de las mujeres tejedoras de esta zona, así como el que demostraban tener los pintores mayas clásicos.

\section{Segunda dimensión: memoria y adaptaciones}

Esta dimensión despliega otra articulación entre la práctica artística textilera, su memoria histórica y las transformaciones provocadas por una economía particular. En este caso se presenta la influencia del concepto de "moda" en la producción de prendas textiles en Los Altos. Se trata de un nuevo eslabón desde el que esta acción artística adquiere un sentido social y contribuye a definir nuevas vertientes que hacen posible nombrar esta práctica artística como un agenciamiento cultural.

Cada una de estas articulaciones nuevas establece vínculos y desenlaces con otras dimensiones, es decir, establece una dinámica de agenciamiento entre un flujo y otro, o entre agenciamientos. Es por ello que la acción artística de los textiles no puede abordarse como una producción de significados cerrados en sí mismos, tal como lo exponen algunos estudiosos, que pretenden descifrar sus formas deslindándolas de las dinámicas sociales que las envuelven.

Los textiles de esta región son prendas históricas en la medida en que aglutinan el pasado y el presente de la comunidad, por ello son parte de una memoria histórica condensada en prendas de vestir de uso diario; se materializan en vestidos que conforman la base para la construcción de la vida cotidiana de los pueblos tsotsiles y tseltales. Con respecto a esta relación entre el vestido y la cotidianidad, Umberto Eco señala:

El vestido es expresivo, es expresivo el hecho de que yo me presente por la mañana en la oficina con una corbata ordinaria a rayas, es expresivo el hecho de que de repente la sustituya por una corbata psicodélica, es expresivo el hecho de que vaya a la reunión de consejo de administración sin corbata [...] La vestimenta, entonces, refleja las condiciones de la vida cotidiana, imprime su sello en la forma de actuar de las variadas circunstancias que nos tocan vivir (Eco, 1976: 34).

La vida cotidiana de los pueblos mayas tsotsiles y tseltales es mediada, entonces, por prendas de vestir que condensan y actualizan su memoria histórica así como su sentir colectivo. Son prendas elaboradas por mujeres como parte de sus actividades domesticas; con estas prendas configuran en el día a día la identidad de su pueblo, y ellas les dan la posibilidad de adaptarse a las circunstancias políticas, sociales y económicas de diversos momentos históricos.

Un ejemplo de esta posibilidad de adaptarse a diversas circunstancias económicas se evidencia en el sentido que desde esta práctica artística se da a la noción de "moda" importada de la económica capitalista. Como parte de las entrevistas realizadas durante el trabajo de campo para esta investigación, dos jóvenes tejedoras mencionaron lo siguiente tras preguntarles sobre su labor.

La primera dijo: "[...] ahorita ya casi no se utiliza el bordado a mano porque es más costoso y lleva mucho tiempo. Entonces, como las flores y los colores también pasan de moda, igual cuando ya lo terminan ya no está de moda ese color y ya no les gusta" (P. López, 12 de mayo de 2013). La segunda joven explicó:

[...] mis hermanos me dicen que ya me ven como viejita porque no estoy a la moda [...] Al 
principio sí les creí y es por eso que las ropas que tenía de los noventa, cuando estaba en la secundaria y una parte de la preparatoria, mi hermana me dijo que las quemara, que ya me veía mal con ellas, y yo creo que me afectó y entonces lo hice (A. Rodríguez, 3 de noviembre de 2012).

En estas respuestas se encuentran dos perspectivas que evidencian estos sentidos: en la primera, la tejedora explica que el bordado hecho a mano es más costoso y su procedimiento es lento, y por eso prefieren hacerlo a máquina para estar acorde con los cambios en la moda relacionados con los tipos de flores y los colores usados en los diseños. En la segunda, la joven describe la exigencia familiar de estar a la moda como un medio para garantizar la aceptación social.

La respuesta de la primera tejedora muestra la relación entre prenda y moda según los conceptos de identidad individual y de progreso propios de la economía mercantil. El filósofo Jean Baudrillard plantea que sólo hay moda en la modernidad, y ello implica un proceso de progreso técnico y de innovación constante. Señala que la modernidad es un código y la moda es su emblema (Baudrillard, 1980). El concepto de moda exalta lo momentáneo y la novedad, simboliza una belleza furtiva y transitoria asociada al progreso. ${ }^{4}$

La idea de lo "progresista" implica un ritmo temporal apresurado en el que la identidad individual se vincula con una concepción de lo pasajero y lo innovador. Estas características inherentes a la dinámica de la moda en el vestir conforman una unidad que construye la personalidad del sujeto. La moda, en este sentido, es principalmente tributaria de un cierto número de significaciones sociales que incluyen la legitimación de lo nuevo y la exaltación personal. Según expone la investigadora Ana Martínez, lo innovador en la moda del vestir concuerda con la aspiración a la autonomía individual y al desarrollo de la personalidad. Lo nuevo crea un sentido de liberación subjetiva de las costumbres pasadas, de ahí el sentido de progreso (Martínez, 1998).

El significado que tal idea adquiere en el marco de las prácticas textiles de los tsotsiles en Los Altos de Chiapas tiene variantes que mezclan la noción de progreso o de autonomía individual con características culturales propias de estos pueblos. Ellos combinan dinámicamente tres elementos: el primero es el sentido de progreso tomado del concepto de moda occidental; el segundo es el uso de procesos de producción textil heredados de cientos de años atrás, y, finalmente, el tercero toma como referencia una actividad propia de su vida cotidiana, el cultivo de flores. ${ }^{5}$

De esta manera, las ideas de "moda" y de "progreso" se adaptan a su propia cosmovisión y, sin suprimirlas, las adecúan a las condiciones históricas que les toca vivir. Entonces, se puede inferir que el concepto de moda se ajusta a la cosmovisión maya de los pueblos originarios de Los Altos de Chiapas.

Esta capacidad de adecuación la han desarrollado a lo largo de su historia como pueblos originarios. La zona de Los Altos de Chiapas se ha caracterizado por ser productora importante de textiles desde antes de la colonización hispánica, y lo siguió siendo durante los periodos de la Conquista, el Virreinato, la guerra de Independencia y la República, hasta la actualidad, gracias a que se ha adaptado a las circunstancias políticas y económicas cambiantes. Se deduce, entonces, que la actividad textil se ha integrado a las nuevas dinámicas de producción, tanto a las traídas por los españoles, como a las originadas en el marco del desarrollo del capitalismo occidental, incluyendo entre éstas las políticas mercantiles de la actualidad.

La práctica textil ha logrado amoldarse y prevalecer en la cultura del pueblo maya durante más de quinientos años debido a que no ha perdido su carácter ritual ni su pertenencia a las actividades cotidianas de los tsotsiles y tseltales. Según estos presupuestos, se puede afirmar que a lo largo de este proceso de adecuación la producción textil se ha transformado y enriquecido sin perder sus rasgos directos de origen prehispánico. Las mujeres tejedoras mayas tsotsiles y tseltales se han apropiado de nuevas técnicas, materias primas, formas de intercambio y, por último, formas de comercialización originadas en la lógica empresarial. 


\section{Tercera dimensión: la acción artística textil como acontecer del día a día}

Las mujeres tejedoras de Los Altos de Chiapas han anudado el vínculo familiar y comunitario a través de los procesos de creación textil, los cuales se enlazan directamente con el vivir cotidiano de sus pueblos. Ellas realizan la práctica textil al mismo nivel que sus actividades domésticas como cocinar, tortear o cuidar animales.

Al preguntar durante las entrevistas sobre el tiempo dedicado a tejer, una joven del municipio de Zinacantán dijo: "Tardo como tres o cuatro días sólo elaborando la tela, tejo de las diez a las cuatro. Después de tejer ya pongo el nixtamal porque aquí torteamos" (P. López, 12 de mayo de 2013). Por otro lado, una mujer tejedora de sesenta años mencionó que: “A veces después de desayunar y darle de comer a los animales ya me pongo a tejer como tres o cuatro horas. A veces empiezo tarde" (C. Pérez, 2 de junio de 2012). Finalmente, al preguntar a una joven sobre la labor de tejido de su madre afirmó:

\footnotetext{
Sólo sé que, levantándose, ella enciende el fuego, hace la tortilla para todas y creo que termina de hacer la tortilla como a las nueve. Después de comer puede ser que ella se vaya a sacar a sus borregos, o si no alguno de sus hijos los saca; y una vez que los borregos ya están afuera comiendo, pues lo que ella hace es tejer o, si no, lavar para que se encojan las faldas. Creo que deja de tejer como a las seis o ya cuando llueve, y después vuelve a encender sus fuegos y a comer nuevamente, ya de noche [...] Mi hermana cuando estálibre se pone a cardar la lana o si no a hilar. Casi así pasa todo el día, por eso nos turnamos para ver los borregos (A. Rodríguez, 3 de noviembre de 2012).
}

La labor textil ha permitido a las mujeres constituirse en sujetos centrales en la construcción y preservación de la cultura del pueblo maya. Este rol protagónico al interior de su cultura se debe a que, entre sus concepciones, el ejercicio de tejer ha sido un acto creativo que forma parte de la actividad doméstica cotidiana. Es decir, las labores del día a día incluyen tiempos en los que las mujeres vinculan una cosmovisión de pensamiento matemático y cósmico con los procesos de cálculo, de observación minuciosa del espacio, de manejos de color y de producción simbólica en la creación de sus prendas.

Se trata, entonces, de un sentir cotidiano en el que las acciones domésticas están cruzadas por un acto de creación expresado en el diseño textil. Así, a pesar de que las acciones de elaborar tortillas o de cuidar animales son en cierto grado mecánicas, están dinámicamente integradas a una actividad que no lo es, pues tejer implica un proceso intelectual complejo y sensible que ocupa un lugar predominante entre las labores domésticas.

\section{A manera de conclusión: resistencia agenciada por mujeres}

Las prácticas artísticas procuradas por mujeres de los pueblos originarios de Los Altos de Chiapas se han convertido en medios para reconstruir y mantener viva su identidad frente a las amenazas de destrucción, en particular las desarrolladas por el capital financiero y las prácticas consumistas de la producción industrial. Y es esto lo que permite visualizar la acción artística de las mujeres como un agente cultural de trasformación en tanto ellas adecúan a sus cosmovisiones las prácticas y valores del sistema económico, político y social dominante.

El arte textil ha sido usado de forma espontánea por los pueblos originarios de Chiapas; se trata de un comportamiento cotidiano que integra aspectos de la producción textil occidental para enriquecer su propia práctica, antes que para eliminarla o sustituirla. Así, el arte textil ha permitido que estos pueblos refuncionalicen una actividad ancestral, adaptándola a su vivir cotidiano actual como pueblo que resiste ante las circunstancias históricas de dominación y explotación que les toca vivir. En este sentido, la práctica textil en Los Altos de Chiapas ha llegado a ser una forma de agenciamiento de gran vigor que ha permitido a las mujeres tsotsiles y tseltales convertirse en fuerza dinámica de resistencia ante las amenazas de absorción o desaparición como pueblos de cultura milenaria. 
Las prendas textiles elaboradas y bordadas en telar de cintura estructuran redes de significados que se actualizan constantemente en la medida en que son prendas de elaboración y uso diarios. El tejido implica una reelaboración permanente de sentidos en los que se aglutinan el pasado y el presente maya, de ahí que la práctica textil y sus productos sean parte de su devenir cultural y no sólo una remembranza de su historia.

\section{Notas}

${ }^{1}$ La noción de "pueblo originario" se asume bajo la consideración de que los grupos tsotsiles y tseltales de Los Altos de Chiapas han ocupado este territorio desde antes de la conquista española hasta la actualidad conservando su lengua de origen maya. Así, los "pueblos originarios" mayenses de esta región se consideran como grupos indios que forman parte de una cultura milenaria.

${ }^{2}$ El análisis descriptivo que se presenta en este artículo de una prenda textil toma como base las explicaciones de las tejedoras entrevistadas y las observaciones participantes hechas durante la celebración del Carnaval de San Pedro, la celebración de Santos Difuntos o la de uso cotidiano durante el trabajo de campo de la investigación. Se hicieron un total de seis entrevistas.

${ }^{3}$ El máxtlatl es una prenda de vestir que consiste en una banda que se enrolla en la cintura y se pasa entre las piernas.

${ }^{4}$ El concepto de progreso en Occidente se utiliza bajo un sentido de ahorro: ahorrar tiempo, ahorrar mano de obra o ahorrar materias primas: ahorros que garantizan una mayor producción. En el caso de la respuesta de la tejedora entrevistada, ella señala la importancia de ahorrar tiempo en la elaboración de prendas textiles.

${ }^{5}$ Las tejedoras mayas que usan diseños de flores en sus bordados son principalmente las del municipio de Zinacantán, quienes a su vez son activas cultivadoras y comerciantes de flores en la región de Los Altos de Chiapas. La joven entrevistada es originaria de este municipio y en sus respuestas menciona el proceso de bordado de las abundantes flores que decoran las prendas de vestir que utilizan diariamente o que venden.

\section{Referencias bibliográficas}

Baudrillard, Jean (1980). El intercambio simbólico y la muerte. Caracas: Monte Ávila.

De la Fuente, Beatriz (1965). La escultura en Palenque. 2 t. México: Instituto de Investigaciones EstéticasUNAM.

Deleuze, Gilles y Felix Guattari (2002). Mil mesetas. Capitalismo y esquizofrenia. Valencia: Pre-Textos.

Eco, Umberto (1976). Psicología del vestir. Barcelona: Lumen.

Larraín, Jorge (2003). "El concepto de identidad". En Famecos, 10(21), agosto: 30-42. Pontificia Universidad Católica del Río Grando del Sol.

Martínez, Ana (1998). Mirar y hacerse mirar. La moda en las sociedades modernas. Madrid: Tecnos.

Pincemin, Sophia (2008). Miradas diferentes o el arte de ver en los murales de Bonampak, Chiapas. Tuxtla Gutiérrez, México: UNICACH. 
Figura 1. Dibujo de Fragmento del tablero del Templo de la Cruz Foliada (basado en el dibujo de Linda Schele de 1976) y dibujo de Mujer de San Pedro Chenalhó con toca

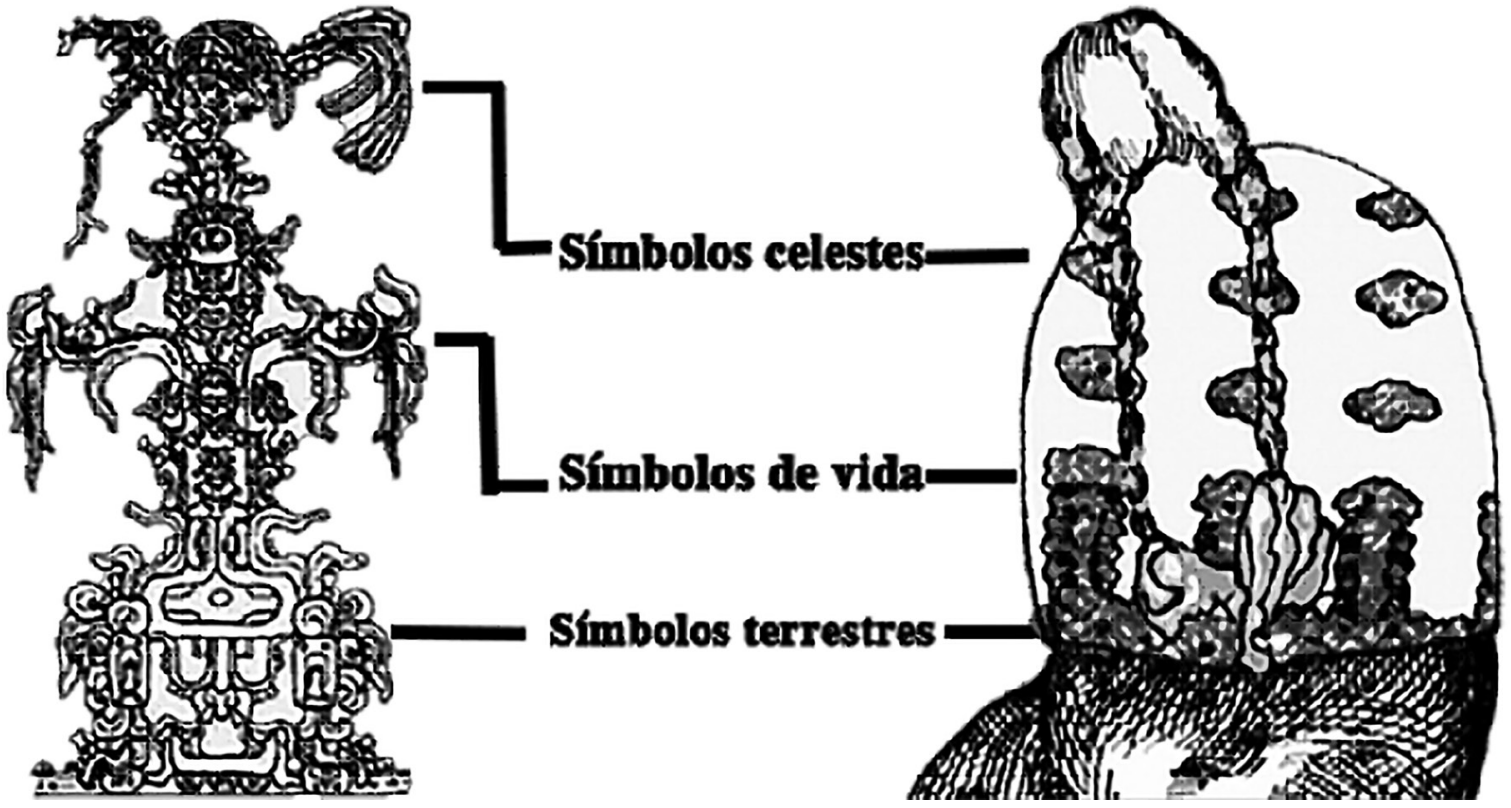

Autor: Andrés Torres Torres. Tinta sobre papel, 2016. 